\title{
LEITURA NO ENSINO MÉDIO: DE QUE MANEIRA AS COMPETÊNCIAS E HABILIDADES DO ENEM ESTÃO SENDO PRATICADAS NOS MATERIAIS DIDÁTICOS? ${ }^{1}$
}

\author{
Silvio Ribeiro da Silva (UFG/Regional Jataí) \\ Kamila Lauany Lucas Lima (UFG/Regional Jataí)
}

Resumo: Neste artigo, apresentamos parte dos dados de uma pesquisa sobre as atividades de leitura e interpretação de textos escritos do material didático (MD) do Sistema Positivo de Ensino (Ensino Médio EM). Partimos do princípio de que a leitura deve ser vista não só como uma atividade interativa, mas também como uma atividade social, cultural e historicamente constituída, associando, a isto, as noções de letramento(s) e a perspectiva de intertextualidade, sendo esta entendida como um recurso interdisciplinar. Duas questões deveriam ser respondidas no estudo que deu origem a este artigo: (i) 0 baixo desempenho dosalunos na avaliação do ENEM, na unidade escolar usuária do MD referido, está associado ao fato de que as atividades de leitura e interpretação apresentadas pelo MD não privilegiam as competências e habilidades requeridas pelo ENEM na área de Linguagens, Códigos e suas Tecnologias?; (ii) 0 baixo desempenho dos alunos se deve a uma metodologia adotada pelo Sistema Positivo de Ensino a qual privilegia o ensino mais normativo, com foco nas atividades de decodificação, abolindo a compreensão ativa, diferentemente da proposta didática do ENEM, a qual leva em conta competências e habilidades, que devem orientar o aluno a uma seleção, organização, relação e interpretação de dados e informações apresentadas de diferentes formas, tendo que tomar decisões e enfrentar situações-problema, por exemplo? A geração e análise dos dados seguiram os princípios metodológicos da pesquisa qualitativo-interpretativista a partir dos pressupostos da Linguística Aplicada. Os dados mostram que o alcance da abordagem feita pelo MD em relação às competências e habilidades mensuradas pelo ENEM ainda é limitado.

1 O estudo que deu origem aos dados que compõem este artigo foi contemplado com bolsa PIBIC/CNPq-2012/2013 e seus resultados contribuem com o Grupo de Estudos da Linguagem: análise, descrição e ensino (UFG/CNPq) e com o grupo de pesquisa Livro Didático de Língua Portuguesa - Produção, Perfil e Circulação (UNICAMP/IEL/CNPq). 
Palavras-chave: Leitura, Interpretação de texto escrito, Material didático, Exame Nacional do Ensino Médio.

Abstract: In this paper we present part of the data of a research about the reading activities and written texts interpretation in the textbooks of "Sistema Positivo de Ensino" (High School). Our basic assumption is that reading must be seen not only as an interactive activity, but also as a social and cultural activity historically constituted associating to this idea the notions of literacy and the perspective of intertextuality, being this one understood as an interdisciplinary resource. Two questions should be answered in the study that led to this paper: (i) Is the low performance of the students in the exam "ENEM" in the school where this textbook is used associated to the fact that the reading and interpretation activities presented by the textbook don't privilege the competences and abilities required by "ENEM" in the field of Languages, Codes and their technologies? (ii) Is the low performance of the students due to the methodology used not adapted by "Sistema Positivo de Ensino" that privileges the teaching in a more normative way, focusing on the activities of decodification abolishing the active comprehension differently from dictatic proposes of "ENEM" which take into consideration competences and abilities that have to guide the student to a selection organization, relation and interpretation of data and information presented in different ways having to take decisions and face problem situations, for example? The generation and analysis of the data followed the methodological principles of the qualitative interpretative research from the assumptions of the Applied Linguistics. The data shows that the range of the approach made by the textbook in relation to the competences and abilities measured by "ENEM" are still limited.

Key-words: Reading, Interpretation of written texts, Textbook, "ENEM".

\section{INTRODUÇÃO}

Neste artigo, apresentamos um recorte dos resultados de uma pesquisa sobre as atividades de leitura e interpretação de textos escritos apresentadas pelo apostilado do Sistema 
Positivo de Ensino (Ensino Médio - EM)², adotado por uma escola da rede privada da cidade de Jataí, Goiás. Os dados fazem parte de uma pesquisa PIBIC/CNPq, desenvolvida nos anos de 2012 e 2013, cujos objetivos centrais foram: (a) analisar se os saberes mobilizados pelas atividades de leitura e interpretação de textos escritos propostas pelo apostilado do Sistema Positivo de Ensino (EM) abordam as competências e habilidades de área exigidas pela avaliação da área de Linguagens, Códigos e suas Tecnologias do Exame Nacional do Ensino Médio (ENEM); e (b) verificar se o insucesso dos alunos da escola com a menor nota na prova da área de Linguagens, Códigos e suas Tecnologias da cidade mencionada pode ter sido causado pelas propostas de leitura e interpretação de textos escritos do Sistema Positivo de Ensino não trabalharem efetivamente o desenvolvimento das competências e habilidades requeridas pelo exame do ENEM ${ }^{3}$.

Nosso interesse pela pesquisa em material didático (MD) se deve ao fato de que ele é um importante objeto de

2 A escolha se deu, dentre outros fatores, por esse ser o sistema de apostilados usado pelo maior número de alunos da cidade de Jataí (GO). Também pelo fato de o Sistema Positivo de Ensino ter um grande alcance, liderando o segmento privado de Educação Básica no país. Em parte dos 10 milhões de alunos que o Grupo Positivo atende em sala de aula, estão os 535 mil alunos do Brasil, Japão e EUA, estudantes de 2.400 escolas que adotam o material elaborado pelo sistema. FONTE: Grupo Positivo Educacional (www.positivo.com.br).

3 Convém não se esquecer de que não é apenas o desempenho na prova que fornece dados para a elaboração dos resultados. São avaliados, também, os dados do Questionário Socioeconômico, respondido pelo candidato no momento da inscrição. Através dele, o participante fornece informações importantes, como sexo, idade, raça/cor, etnia, nível de escolaridade dos pais, etc. 
estudo, o qual traz conteúdos de diversas áreas do saber. Por isso, a formulação de seus conteúdos deve constituir um rico material de pesquisa; e isto pode contribuir com a melhoria do processo de ensino-aprendizagem.

O ENEM é uma avaliação em larga escala. Leva em conta o uso de competências e habilidades específicas e avalia seu uso na leitura ou na produção escrita ${ }^{4}$. O aluno deve, na prova do ENEM, dentre outras habilidades, identificar os elementos que concorrem para a progressão temática e para a organização e estruturação de textos de diferentes gêneros e tipos. O enfoque principal do ENEM é dar acesso aos seus participantes ao ensino superior. Por isso, seus objetivos específicos vão ao encontro da proposição de avaliações que conduzam cada cidadão à sua autoavaliação em relação às suas escolhas futuras, possibilitando, assim, opções e acessos a diferentes setores do mundo de trabalho e a cursos profissionalizantes.

O resultado do ENEM que interessou a este estudo é aquele referente às escolas privadas da cidade de Jataí, situada no sudoeste do estado de Goiás, onde, das 08 (oito) unidades escolares cujos alunos fizeram a avaliação em 2011, 07 (sete) tiveram um índice de participação de estudantes igual ou

\footnotetext{
4 A avaliação por competência não prioriza uma nota, mas traz informações necessárias sobre o processo de ensino/aprendizagem para que o aprendiz possa ampliar seus conhecimentos (LUCKESI, 2008).
} 
superior a $75 \%^{5}$. O Instituto Samuel Graham (usuário de apostilado do Sistema Positivo de Ensino no ano de geração dos dados) obteve a menor média em Linguagens, Códigos e suas Tecnologias ${ }^{6}: 566,50$.

Para o alcance dos objetivos propostos, este artigo está dividido em quatro partes. Inicialmente, apresentamos como se deu o processo de geração de dados, ocorrido no segundo semestre de 2012 e primeiro de 2013. Na sequência, falamos sobre a estrutura arquitetônica do material didático em observação e apresentamos nossas considerações de ordem quantitativa e qualitativa sobre os dados, concluindo com as considerações finais, que preferimos não chamar de conclusões, já que trazem, ainda, pontos de vista qualitativos de nossa parte. Por fim, aparece a lista de referências bibliográficas.

\section{A GERAÇÃO DOS DADOS}

Para a geração e análise dos dados, os procedimentos metodológicos de pesquisa adotados são aqueles provenientes da Linguística Aplicada (LA), enquadrando o estudo na perspectiva qualitativo-interpretativista. As

\footnotetext{
5 O valor percentual faz referência ao montante de 29 alunos que participaram da avaliação. FONTE: Portal INEP: http://sistemasenem2.inep.gov.br/enemMediasEscola/

6 Convém esclarecer que estamos interessados apenas pela pontuação referente à prova de leitura da área de Linguagens, Códigos e suas Tecnologias, já que a prova de Redação avalia outras competências e focamos aquelas que dizem respeito à leitura especificamente.
} 
categorias que serviram de base para a análise dos dados são oriundas da matriz de competências e habilidades da área de Linguagens, Códigos e suas Tecnologias, do componente curricular Língua Portuguesa e Literatura, do ENEM, referente ao ano de $2011^{7}$.

A matriz de competências e habilidades do ENEM é de responsabilidade do Instituto Nacional de Estudos e Pesquisas Educacionais Anísio Teixeira (INEP). Seu objetivo é operacionalizar o exame. De acordo com o Ministério da Educação, as competências e habilidades avaliadas focam um aluno que está numa fase de desenvolvimento cognitivo correspondente à conclusão da escolaridade básica e os conteúdos curriculares são associados àqueles trabalhados ao longo do Ensino Fundamental e Médio.

Inicialmente, procedemos a um mapeamento dos gêneros apresentados ao aluno pelo MD para leitura e interpretação de texto escrito. O intuito desse mapeamento foi julgar a existência ou não de sua diversidade, já que, quanto mais diversidade de gêneros houver, maiores benefícios terá o aluno num programa de ensino de Língua.

7 Não foram todas as competências da área de Linguagem, Códigos e suas Tecnologias que interessaram a este estudo. Desconsidero aquelas mais voltadas a aspectos da Arte, ou a Práticas Corporais, por exemplo. Dados completos sobre o conteúdo referente às competências e habilidades da prova da área de Linguagem, Códigos e suas Tecnologias disponíveis em http:// download.inep.gov.br/educacao_basica/enem/downloads/2012/matriz_referencia_enem.pdf 
As competências e habilidades mensuradas pela prova do ENEM foram usadas como categorias de análise quantitativa e qualitativa no estudo original. Para as considerações de ordem quantitativa, apresentamos dados percentuais, mostrando a quantidade de atividades, em relação a um valor total, que se relacionam diretamente com as competências e habilidades. Já nas considerações de ordem qualitativa, trazemos questões apresentadas ao aluno pelo apostilado, as quais ilustram o uso dessas competências e habilidades.

Neste artigo, apresentamos dados acerca da competência 8 e suas habilidades, presentes no MD usado pelos alunos da $2^{a}$ série, problematizando, com base em teóricos da área, o que as atividades podem proporcionar ao aluno para a ampliação ou não de seu(s) letramento(s) vinculados a esta competência ${ }^{8}$.

Os dados são aqui apresentados da seguinte forma: primeiro, o número de atividades por seção e por habilidades (de todo o MD); em seguida, exemplos ilustrativos com comentários analíticos. Por mais que o número de exemplos para cada caso seja restrito, isso não representa prejuízo ao leitor, já que o conjunto de atividades apresentado pelo MD costuma seguir sempre o mesmo estilo didático.

8 A abordagem feita apenas em relação à competência 8 e suas habilidades, somente na $2^{a}$ série, se deve à limitação de espaço disponível. 
Dizemos isso porque, segundo Bunzen \& Rojo (2005), existe certa regularidade na forma de composição e estilo de gênero em MD. Dentre essas regularidades, os autores citam a intercalação de textos de gêneros e esferas variados, regidos e articulados para certo efeito de sentido pelo projeto, pela voz, pelo discurso autoral, bem como a divisão do MD em capítulos ou unidades, seções e subseções, dentro das quais os temas são selecionados a partir de um projeto autoral. Para os pesquisadores, as escolhas feitas pelos autores de MD, certamente em comum acordo com os editores, refletem uma apreciação de valor a respeito do que é e de como se faz o ensino de língua materna.

As três habilidades vinculadas à competência 8 dizem respeito à língua em uso, considerando que ela é geradora de significação e participa, ainda, da organização do mundo e da identidade de quem a utiliza. O MD pouco colabora com o aluno se tratar desses aspectos de maneira superficial. Com isso, desfavorece a ampliação do seu entendimento em relação às significações que a língua pode adquirir. Da mesma forma, dificulta que o aluno (re)pense as questões referentes ao uso, ainda mais se pensarmos em atribuir à língua parte do caráter identitário do falante.

O ponto central das habilidades associadas à competência 8 é a variação linguística. A atividade que leva em conta as 
variedades no uso da língua é colaborativa, tendo em vista que um dos objetivos do ensino de Língua Portuguesa é justamente discutir o respeito às diferentes variedades do Português. Depois da publicação dos Parâmetros Curriculares Nacionais $(1997,1998)$ e das Orientações Curriculares para o Ensino Médio (2006), a ideia de que é preciso abordar com os alunos a questão das variações no uso da língua ganhou mais destaque. Há um bom tempo deixou de ser prioridade apenas o trabalho com a variedade considerada padrão, buscando somente o ensino de seu domínio, sem considerar os demais usos e sem levar em conta que o uso linguístico varia de acordo com o contexto ${ }^{9}$. A importância de se promover na sala de aula um debate sobre a variação das línguas no aspecto temporal e espacial, bem como trazer à tona o esclarecimento de sua modificação ao longo do tempo, é incontestável.

É de conhecimento coletivo ser dispensável o ensino da norma não-padrão. Por outro lado, é necessário conscientizar o aluno acerca da questão de que o uso varia por conta da situação e da pessoa (contexto de produção e contexto de recepção) a quem se dirige aquilo que se fala ou se escreve.

9 Do ponto de vista da abordagem de Bakhtin ([1952-53]1979), a esfera em que o interlocutor está, bem como a figura deste interlocutor, são elementos essenciais para que o enunciado a ser produzido seja mais ou menos complexo (secundário ou primário, respectivamente). Nesse sentido, o uso linguístico vai variar de acordo com o ambiente onde os usuários se encontram, bem como quem são os interlocutores. 
Entendemos por competência aquilo que é necessário para o enfrentamento de determinada situação. Cabe enfatizar que a competência não é simplesmente o uso de algo aprendido. Ela engloba uma capacidade de poder usar inúmeros recursos no momento em que estes forem necessários, de forma que produzam os efeitos pretendidos.

Já a habilidade é entendida como a capacidade de promover transformações, fazendo com que um conhecimento seja caracterizado como uma ação, dando origem a um desempenho.

\section{OS DADOS MOSTRAM A QUE VIERAM}

Iniciamos esta parte pelos gêneros apresentados ao aluno nas seções que o referido material considera específicas para o trabalho com a leitura e a interpretação de textos escritos. O MD afirma que (p. 01 - Livro do Professor - LP) explora um vasto conjunto de gêneros. Para Dolz, Noverraz \& Schneuwly ([2001]2004), se o objetivo educacional for desenvolver eficientemente uma diversidade de capacidades de linguagem, com o aluno devem ser trabalhados gêneros pertencentes a agrupamentos diferentes ${ }^{10}$, sempre considerando o ensino-aprendizagem da modalidade oral,

10 Segundo Dolz \& Schneuwly ([1996]2004), agrupamento se refere à montagem de sequências didáticas que tragam determinado número de gêneros agrupados de acordo com os aspetos tipológicos e capacidades de linguagens dominantes no gênero. Na proposta dos autores, esses aspectos tipológicos são narrar, relatar, argumentar, expor e descrever ações. 
ainda tão deixada de lado atualmente ${ }^{11}$. Ao pensar em uma sequência de gêneros que serão objeto de ensino com o aluno, os objetivos pretendidos para cada série e o grau de dificuldade ou facilidade que aqueles gêneros podem representar ao aluno devem ser considerados.

O MD traz ao aluno os seguintes gêneros para a leitura e a interpretação por série ${ }^{12}$ : 1a - Notícia; Reportagem; Crônica; Conto fantástico; Anúncio publicitário; Artigo de opinião; Crônica; Carta do leitor; Carta ao leitor. 2a - Resenha; Texto de divulgação científica; Poema; Jingle; Editorial; Charge; Cartum; Diário de viagem; Artigo de opinião. 3a - Artigo de opinião; Carta argumentativa; Currículo; Artigo científico; Reportagem dissertativa; Texto informativo/dissertativo.

Os aspectos tipológicos, segundo proposta de Dolz \& Schneuwly ([1996]2004), em ordem decrescente de ocorrência são: argumentar, relatar, expor e narrar ${ }^{13}$. O sistema Positivo apresenta um conjunto satisfatório de gêneros, enquadrados na maioria dos aspectos tipológicos. Assim, oportuniza ao aluno a ampliação de sua coletânea de capacidades linguísticas mediante o contato com um bom número de gêneros ao longo

11 A respeito da consideração dos autores acerca do trabalho com a modalidade oral, cabe comentar que o sistema Positivo pouco trabalha com o desenvolvimento das capacidades vinculadas a esse eixo de ensino.

12 Não foram considerados os gêneros apresentados nas demais seções não específicas de leitura e interpretação.

13 O aspecto tipológico 'descrever ações' não aparece. 
dos três anos do EM, não se perdendo de vista, obviamente, que apenas ser apresentado a um gênero não significa sua apreensão. Para a apreensão eficiente, a didatização feita pelo professor jamais pode ser desconsiderada.

No que se refere ao montante de atividades em que são mobilizadas competências e habilidades, por seção, em todo o MD, temos o seguinte ${ }^{14}$.

\begin{tabular}{|c|c|c|c|}
\hline Seção & $\begin{array}{c}\text { Total de } \\
\text { atividades }\end{array}$ & $\begin{array}{c}\text { Total de } \\
\text { habilidades } \\
\text { mobilizadas }\end{array}$ & Percentual \\
\hline Entrando na rede & 150 & 34 & $23 \%$ \\
\hline Nas malhas do texto & 147 & 38 & $26 \%$ \\
\hline Relacionando & 85 & 22 & $26 \%$ \\
\hline Comparando & 62 & 16 & $26 \%$ \\
\hline Tecendo ideias & 52 & 5 & $10 \%$ \\
\hline Total geral & 496 & 115 & $23 \%$ \\
\hline
\end{tabular}

Tabela 1: Valores percentuais das habilidades por seção

Pelos números, nota-se que a seção com mais ocorrência de atividades é 'Entrando na rede'. 'Nas malhas do texto' é a que apresenta o maior conjunto de habilidades em uso. Os dados mostram que o percentual de atividades que mobilizam habilidades em cada uma das seções é bastante reduzido. Se o fato de não trabalhar efetivamente com as

14 Ressaltamos que a amostragem geral diz respeito às competências 5 a 8 e respectivas habilidades. O motivo dessa consideração é a crença de que apresentar os dados em relação a todas as competências e habilidades pode dar ao leitor uma visualização mais consistente acerca dos dados, instigando-o a uma análise das reais contribuições do material em observação para a aquisição e/ou ampliação dos letramentos necessários para a obtenção de um resultado favorável no ENEM. 
habilidades for um dos motivos do baixo desempenho dos alunos na avaliação, os dados, até aqui, dão um indício do porquê a unidade escolar usuária do material do Sistema Positivo obteve a menor nota em Linguagens, Códigos e suas Tecnologias na avaliação de 2011.

Como já dito, apresentaremos dados qualitativos da 2a série, referentes apenas à competência 8 e respectivas habilidades (25, 26 e 27), as quais são:

\begin{tabular}{|c|c|}
\hline Competência & Habilidades relacionadas \\
\hline $\begin{array}{l}8 \text { - Compreender } \\
\text { e usar a língua } \\
\text { portuguesa como } \\
\text { língua materna, } \\
\text { geradora de }\end{array}$ & $\begin{array}{l}\text { H25 - Identificar, em textos de } \\
\text { diferentes gêneros, as marcas } \\
\text { linguísticas que singularizam as } \\
\text { variedades linguísticas sociais, regionais } \\
\text { e de registro }\end{array}$ \\
\hline $\begin{array}{l}\text { significação e } \\
\text { integradora da } \\
\text { organização }\end{array}$ & $\begin{array}{l}\text { H26 - Relacionar as variedades } \\
\text { linguísticas a situações específicas de } \\
\text { uso social }\end{array}$ \\
\hline $\begin{array}{l}\text { do mundo e da } \\
\text { própria identidade }\end{array}$ & $\begin{array}{l}\text { H27 - Reconhecer os usos da norma } \\
\text { padrão da língua portuguesa nas } \\
\text { diferentes situações de comunicação }\end{array}$ \\
\hline
\end{tabular}

Figura 1: Competências e habilidades em análise

Do ponto de vista da quantidade de ocorrências por habilidade, associada somente à competência 8, em relação ao montante total de atividades (115), os dados gerados são os seguintes: 


\begin{tabular}{|c|c|c|c|}
\hline Competências & Habilidades & Ocorrências & Percentual \\
\hline \multirow{3}{*}{8} & $\mathrm{H} 25$ & 15 & $13 \%$ \\
\cline { 2 - 4 } & $\mathrm{H} 26$ & 12 & $10 \%$ \\
\cline { 2 - 4 } & $\mathrm{H} 27$ & 8 & $7 \%$ \\
\cline { 2 - 4 } & Total & $\mathbf{3 5}$ & $\mathbf{3 0 \%}$ \\
\hline
\end{tabular}

Tabela 2: Valores percentuais das habilidades

Nota-se que a abordagem das habilidades referentes à competência 8 é bem pequena ao longo do MD, especialmente em relação à habilidade 27 , relacionada à variedade linguística.

A atividade que apresentamos como ilustrativa para a habilidade 25 está na seção 'Relacionando', integrante do Vol. $2^{15}$. A atividade 2 faz referência a fragmentos de editoriais, extraídos de dois jornais: Correio Brasiliense e Infocampus, ambos publicados em 2007.

Identificar, em textos de diferentes gêneros, as marcas linguísticas que singularizam as variedades linguísticas sociais, regionais e de registro

Que elementos textuais tornam o primeiro trecho mais formal, se comparando ao segundo? [p. 5]

Figura 2: Atividade ilustrativa para a habilidade 25

A resposta esperada apresentada pelo livro do professor (LP, p. 2) indica que as diferenças entre os trechos se devem às escolhas lexicais e a construções sintáticas curtas e de efeito, mas não há especificação do que motivou tais escolhas. Da

15 A título de esclarecimento, informamos que cada série é composta por 4 volumes. 
forma como a resposta esperada é apresentada, percebe-se que o MD atribui a caracterização mais formal de um fragmento de texto exclusivamente ao próprio texto, sem priorizar a situação de uso, a qual, dentre outros aspectos, "determina tanto o grau de formalidade e o registro utilizado quanto a modalidade de uso, se falada ou escrita" (BRASIL, 2006, p. 20).

Ser mais ou menos formal num enunciado depende de uma série de fatores, como dito há pouco, muitos deles associados a aspectos inerentes ao gênero escolhido, à esfera de circulação daquele gênero e, principalmente, aos interlocutores.

No caso do primeiro fragmento, seu interlocutor e sua esfera de circulação são mais formais (leitores do jornal Correio Brasiliense). Assim, é muito mais visível que a sua caracterização como um gênero do discurso secundário (mais formal e complexo) foi motivada por essas condições. No caso do segundo fragmento, seu interlocutor e sua esfera de circulação (leitores de um jornal acadêmico de uma instituição tecnológica do estado do Paraná) fazem com que, do ponto de vista estilístico, as escolhas do autor sejam menos elaboradas, fazendo do editorial em questão um gênero do discurso primário. Nesse sentido, podemos notar que a maior formalidade atribuída ao primeiro fragmento apresentado passa longe de ser uma 'opção' do próprio texto, 
como deixa a entender a resposta esperada apresentada pelo LP, mas recebeu um tratamento estilístico associado a fatores vinculados ao interlocutor e à esfera de circulação, considerando que, segundo Bakhtin ([1952-53] 1979, p. 284-5),

Cada esfera conhece seus gêneros, apropriados à sua especificidade, aos quais correspondem determinados estilos. Uma dada função (científica, técnica, ideológica, oficial, cotidiana) e dadas condições, específicas para cada uma das esferas da comunicação verbal, geram um dado gênero, ou seja, um dado tipo de enunciado, relativamente estável do ponto de vista temático, composicional e estilístico. O estilo é indissociavelmente vinculado a unidades temáticas determinadas e, o que é particularmente importante, a unidades composicionais: tipo de estruturação e de conclusão de um todo, tipo de relação entre o locutor e os outros parceiros da comunicação verbal (relação com o ouvinte, ou com o leitor, com o interlocutor, com o discurso do outro, etc.). (grifo nosso).

Ainda segundo Bakhtin ([1952-53]1979, p. 324),

A concepção que o locutor (ou o escritor) faz do destinatário do seu discurso é um problema importantíssimo na história da literatura. Cada época, cada movimento literário, cada estilo artístico-literário, cada gênero literário, nos limites de uma época e de um movimento, se caracteriza por sua concepção particular do destinatário da obra literária, por uma percepção e uma compreensão particulares do leitor, do ouvinte, do público, da audiência popular. 
Mesmo não sendo uma obra literária, já que os fragmentos apresentados vêm de dois jornais, nota-se a importância a ser atribuída à pessoa que recebe o enunciado, fato que não foi considerado pelo MD. No LP inexistem quaisquer considerações acerca disso. Caberia ao professor, durante o processo de didatização, fazer as devidas considerações ao aluno em relação ao papel primordial exercido pelo interlocutor nas escolhas estilísticas deste.

A atividade ilustrativa para a habilidade 26 está na seção 'Nas malhas do texto', integrante do Vol. 4. A atividade 8b faz menção a um fragmento da matéria $O$ eterno retorno da bruxa genial da introspeç̧ão, escrito por Marina Colasanti, a propósito da reedição da obra de Clarice Lispector.

Relacionar as variedades linguísticas a situações específicas de uso social

A expressão a gente é muito utilizada no português falado atualmente, para fazer referência a nós ( $1^{a}$ pessoa do plural). Além do princípio da eufonia, que alerta para a sonoridade ambígua de a gente/agente, é preciso notar a ocorrência frequente de construções do tipo: "a gente fomos". B) Qual poderia ser a razão para a ocorrência do uso do verbo no plural após a expressão a gente? [p. 17]

Figura 3: Atividade ilustrativa para a habilidade 26

A primeira percepção que temos em relação à questão diz respeito à ausência de considerações mais esclarecedoras 
acerca do que vem a ser eufonia (sucessão harmoniosa de sons). No LP não ocorrem quaisquer comentários que orientem o professor a fazer isso. Analisando todo o MD, não encontramos nenhuma seção em que ocorre discussão a respeito do conceito de eufonia. Ficaria a cargo do professor o processo de didatização que consiga esclarecer melhor ao aluno do que se trata, já que consideramos a 'explicação' do MD muito superficial.

A atividade apresentada gira em torno da relação 'uso normativo $x$ uso não normativo'. A intenção central que pode ser depreendida da forma como a atividade é apresentada ao aluno é a de chamar a atenção para a pluralização do que vem após a expressão 'a gente', indicativa da presença de mais de uma pessoa no discurso.

O uso de 'a gente' para exprimir 'nós' vai ao encontro de um aspecto da dêixis de pessoa. Para Benveniste (2006), é fundamental no discurso a presença do dêitico de pessoa. Para o autor, no momento em que alguém enuncia algo, designa para si mesmo um eu e estabelece, ao mesmo tempo, a figura do $t u$, que pode "ser presente ou ausente, existente ou inexistente" (FIORIN, 2002, p. 42). Diz, ainda, que a dêixis de pessoa é a responsável pela indicação dos referentes que assumem os papéis de primeira e segunda 
pessoas. Em geral, a dêixis de pessoa se estabelece com o uso de pronomes pessoais e possessivos.

Um aspecto que acabou não privilegiado pela atividade diz respeito a que efeitos de sentido estão por trás da presença marcante daquele que enuncia, levando em conta que a expressão 'a gente' introduz no enunciado pelo menos mais uma pessoa, o que faz com que ele deixe de ser monolítico (quando não se dirige a um interlocutor), indicando que a enunciação não é somente do próprio locutor (pelo menos em tese); considerações também relevantes ao invés de apenas trabalhar com a noção de pluralização presente na expressão 'a gente'.

A atividade ilustrativa para a habilidade 27 está na seção 'Entrando na rede', integrante do Vol. 3. A atividade $6 \mathrm{faz}$ referência a trechos do livro As vozes de Marrakech, de Elias Canetti, publicado em 2006.

Reconhecer os usos da norma padrão da língua portuguesa nas diferentes situações de comunicação

Os trechos apresentam uma linguagem culta e uma percepção minuciosa dos fatos ocorridos. Justifique o motivo da utilização dessa linguagem. [p. 4]

Figura 4: Atividade ilustrativa para a habilidade 27

Ao indicar que a percepção minuciosa acerca de determinados fatos ocorreu com o uso de uma linguagem 
culta, o enunciado da questão dá a entender que o uso de outro tipo de variedade impediria a percepção minuciosa.

A resposta esperada, apresentada pelo $L P$, indica que 0 autor do texto em estudo é um renomado escritor ${ }^{16}$. Isso possibilita interpretar que ele possui vasta experiência e intimidade com a escrita. Segundo o MD, por mais que se trate de um texto menos formal, o estilo de escrita do autor não se modifica. Nesse sentido, notamos que o autor desconsidera o interlocutor (e a esfera) para quem o referido texto é feito, já que, pelo que o MD diz, ele sempre usa o mesmo estilo, ancorando o texto num gênero de aspecto secundário. Interpretamos esse fato como uma tentativa do autor de manter sempre a consciência nítida daquilo que escreve, levando em conta apenas a si mesmo, numa atitude quase egoísta acerca da individualidade do sujeito.

Não houve menção ao uso da linguagem formal associada ao gênero, ao interlocutor e à esfera de circulação do referido gênero, o que poderia ampliar a consciência linguística do aluno em relação aos usos e ao estilo linguístico adotados. Ressaltar para o aluno o uso linguístico torna-se mais relevante se não se ficar apenas na observação da "existência de certos estilos de linguagem, dialetos sociais, etc., existência essa estabelecida por meio de critérios meramente linguísticos" 16 O autor é Elias Canetti, escritor búlgaro, ganhador do Prêmio Nobel de Literatura em 1991. 
(BAKHTIN, [1929]2010, p. 215). Também é relevante chamar sua atenção para o 'ângulo dialógico' estabelecido pela escolha estilística. O ângulo dialógico indica o 'ir-além' do puramente linguístico, pois pertence à língua enquanto fenômeno integral concreto. Assim, uma escolha estilística deve considerar a relação dialógica, o "que constitui o verdadeiro campo da vida da linguagem" (BAKHTIN, [1929] 2010, p. 217).

\section{ENCERRANDO A CONVERSA - MAS NÃO O ASSUNTO}

O principal objetivo deste artigo foi analisar de que modo os saberes mobilizados pelas atividades de leitura e interpretação de textos escritos propostas pelo apostilado do Sistema Positivo de Ensino (EM) da $2^{a}$ série vão ao encontro da competência 8 e respectivas habilidades exigidas pela avaliação da área de Linguagens, Códigos e suas Tecnologias do ENEM, componente Língua Portuguesa e Literatura.

Convém esclarecer que as perguntas apresentadas no resumo inicial são as que motivaram o desenvolvimento de todo o estudo que deu origem aos dados aqui apresentados. A intenção deste texto, porém, não foi apresentar respostas àquelas perguntas, já que nosso objetivo aqui esteve voltado tão somente a direcionar o olhar analítico para as habilidades da competência 8, como dito há pouco. 
Os dados gerados mostraram que a referida competência e suas habilidades são pouco abordadas do ponto de vista quantitativo, e quando são (do ponto de vista qualitativo) pouco contribuem para que o aluno da $2^{a}$ série entenda aspectos relacionados à língua em uso e seu papel enquanto geradora de sentido e uma das responsáveis por nossas marcas de identidade.

O principal objetivo de se trabalhar na escola com a questão da variação sobre a língua é mostrar que as manifestações linguísticas reais não são uniformes, estanques (como entende e divulga a Gramática Normativa); mas sim heterogêneas, multifacetadas e plurais, como são aqueles que as usam. Dito de outra forma, o ensino da variação linguística objetiva mostrar que quando usamos a língua de maneira protagonista, autônoma, necessitamos de um conjunto de letramentos que não sejam somente aqueles ligados ao padrão normativo. Um dos propósitos da escola é dotar o aluno da consciência acerca desses outros letramentos, bem como acerca da forma de colocá-los em uso.

A abordagem sobre a variação a respeito da língua é imprescindível num programa de ensino que considere o uso, já que é nessa situação concreta que as marcas típicas da variação acontecem, ainda mais quando se trata de uma 
língua usada por um país de extensão territorial tão ampla como o Brasil. O que ainda merece melhor problematização é o fato de que, em geral, a escola, uma importante agência de letramento, aborda a variação apenas com a apresentação da dicotomia certo $x$ errado, sem considerar os usos não categorizados como padrão, os quais marcam muito mais a identidade dos usuários do idioma, porque sabemos que a língua padrão baseada nos princípios da gramática normativa é uma 'encenação teatral' e longe de ser a língua real ${ }^{17}$.

Para que ocorra um trabalho eficiente com essa língua real, há de se considerar, num programa de ensino, o trabalho com a oralidade, ou pelo menos a valorização desta, já que todos nós vivemos a língua muito mais na oralidade do que na escrita, sem deixar de lado o fato de que muitos brasileiros ainda não vivem a língua escrita de forma autônoma. É Labov (2008, p. 13) quem vai apresentar argumento de autoridade em relação a isso ao dizer que é na fala "que as pessoas discutem com seus cônjuges, brincam com seus amigos e ludibriam seus inimigos". Assim, é na fala que a interação ocorre de fato (pelo menos na maioria das vezes e para a maioria de nós).

Porém, a valorização da oralidade na escola ainda é

17 Ressaltamos que as atividades apresentadas aqui não levam em conta a relação certo $x$ errado. $O$ que queremos enfatizar neste parágrafo é a prática ainda comum na escola de considerar os usos linguísticos apontando apenas esta relação. 
incipiente. Nas atividades apresentadas como ilustração para as habilidades da competência 8 , notamos que a maior aproximação existente com a língua em uso numa situação de fala ocorreu no segundo exemplo, mas de maneira ineficiente, já que o texto apresentado é escrito. O que acontece é apenas um simulacro de língua em uso.

Será a escola, pelo fato de ser um espaço onde se dá o processo de socialização, a esfera onde haverá uma considerável diversidade, inclusive linguística. $\mathrm{Na}$ atual conjuntura social em que nos encontramos, o convívio multicultural é algo sempre presente e isso pressupõe o respeito ao outro, à sua linguagem.

Pensando em tudo isso numa perspectiva letrada, Hamilton (2002) nos diz acerca dos letramentos dominantes, institucionalizados e valorizados, dentro dos quais estão as variedades linguísticas e registros considerados padrão, bem como a gramática normativa. Na contramão dessa ideia, estão os letramentos locais, ou vernaculares, dentro dos quais estão as variedades e registros considerados não padrão.

Para Hamilton (2002), os letramentos vernaculares são originários da vida cotidiana, doméstica e partem das culturas locais. São, portanto, desvalorizados culturalmente. Daí não fica difícil entender por que tudo que diz respeito aos usos não padrão da linguagem é considerado como inferior. 
Rojo (2009) diz que nos últimos tempos os estudos de letramento têm se voltado para os letramentos locais ou vernaculares. Dessa forma, deveria haver uma maior intensidade de estudos acerca dos usos linguísticos considerados não padrão, já que estes letramentos vão ao encontro desse tipo de uso. Porém, grande parte desses estudos reforça que os usos padrão são superiores e deveriam ocupar a maior parte das práticas linguísticas.

Rojo (2009) afirma, ainda, que um dos objetivos principais da escola é o de possibilitar que os alunos participem de inúmeras práticas sociais, dentro das quais haverá (ou pelo menos deveria haver) variados usos linguísticos. Fazendo isso, a escola pode(ria) contribuir com uma melhor compreensão acerca da variedade de usos e registros linguísticos possíveis.

Esperamos que este cenário escolar comece a existir rapidamente.

\section{REFERÊNCIAS}

BAKHTIN, M. (1929). Problemas da poética de Dostoiévski. Trad. Paulo Bezerra. 5ed. Rio de Janeiro: Forense Universitária, 2010. . (1952-53). "Os gêneros do discurso". In . Estética da criação verbal. São Paulo: Martins Fontes, 1979. p. 277-326.

BENVENISTE, E. (2006) Problemas de linguística geral I. 5ed. Campinas, SP: Pontes. BRASIL (SEF/MEC). (1997) Parâmetros curriculares nacionais $-1^{\circ}$ e $2^{\circ}$ Ciclos do Ensino Fundamental. Língua Portuguesa. Brasília, DF: SEF/MEC. BRASIL (SEF/MEC). (1998) Parâmetros curriculares nacionais - $3^{\circ}$ e $4^{\circ}$ 
Ciclos do Ensino Fundamental. Língua Portuguesa. Brasília, DF: SEF/MEC. BRASIL/MEC/SEB. (2006) Orientações curriculares para o ensino médio: Linguagens, códigos e suas tecnologias. Secretaria de Educação Básica. - Brasília: Ministério da Educação, Secretaria de Educação Básica. p. 239. BUNZEN, C. \& ROJO, R. H. R. (2005) "Livro didático de língua portuguesa como gênero do discurso: autoria e estilo". In COSTA VAL, M. G. \& MARCUSCHI, B. (org.). O livro didático de língua portuguesa - letramento, inclusão e cidadania. Belo Horizonte: Autêntica. p. 73-117.

DOLZ, J. \& SCHNEUWLY, B. (1996). "Gêneros e progressão em expressão oral e escrita: elementos para reflexões sobre uma experiência suíça (francófona)". In SCHNEUWLY, B., DOLZ, J. et al. (2004) Gêneros orais e escritos na escola. Campinas: Mercado de Letras, p. 41-70.

DOLZ, J., NOVERRAZ, M. \& SCHNEUWLY, B. (2001). "Sequências didáticas para o oral e a escrita: apresentação de um procedimento". In SCHNEUWLY, B., DOLZ, J. et al. (2004) Gêneros orais e escritos na escola. Campinas: Mercado de Letras. p. 95-128.

FIORIN, J. L. (2002) As astúcias da enunciação. São Paulo: Ática.

FURTADO, E. M., KOLB, C. W., NEMITZ, V. [et al.] (2008) Língua Portuguesa: ensino médio. 1aㅡ, 2a , 3a séries. Curitiba: Positivo.

HAMILTON, M. (2002) "Sustainable literacies and the ecology of lifelong learning". In HANSON, A. and CLARKE, J. (org.) Supporting lifelong learning, Volume 1: Perspectives on Learning. Routledge/Open University Press, p. 176-187.

LABOV, W. (2008) Padrões sociolinguísticos. São Paulo: Parábola Editorial. LUCKESI, C. C. (2008) Avaliação da aprendizagem escolar. São Paulo: Cortez.

ROJO, R. H. R. (2009) Letramentos múltiplos, escola e inclusão social. São Paulo: Parábola Editorial.

Sílvio Ribeiro da Silva graduado em Letras, mestre em Linguística, doutor em Linguística Aplicada, professor na Universidade Federal de Goiás/Regional Jataí. Contato: shivonda@gmail.com 
Kamila Lauany Lucas Lima cursa Ciências Biológicas na Universidade Federal de Goiás/Regional Jataí. Foi bolsista PIBIC/CNPq. Atualmente é bolsista PIBID.

Recebido em 19 de junho de 2014. Aprovado em 22 de agosto de 2014. 